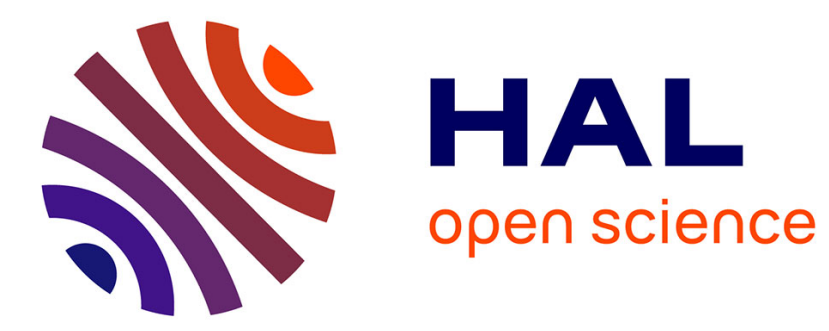

\title{
Socioeconomic inequality in tobacco use in Kenya: a concentration analysis
}

Hermann Pythagore Pierre Donfouet, Shukri F. Mohamed, Eric Malin

\section{To cite this version:}

Hermann Pythagore Pierre Donfouet, Shukri F. Mohamed, Eric Malin. Socioeconomic inequality in tobacco use in Kenya: a concentration analysis. International Journal of Health Economics and Management, 2021, 21 (2), pp.247-269. 10.1007/s10754-020-09292-0 . hal-03127785

\section{HAL Id: hal-03127785 \\ https://hal.science/hal-03127785}

Submitted on 22 Nov 2021

HAL is a multi-disciplinary open access archive for the deposit and dissemination of scientific research documents, whether they are published or not. The documents may come from teaching and research institutions in France or abroad, or from public or private research centers.
L'archive ouverte pluridisciplinaire HAL, est destinée au dépôt et à la diffusion de documents scientifiques de niveau recherche, publiés ou non, émanant des établissements d'enseignement et de recherche français ou étrangers, des laboratoires publics ou privés.

\section{다)(1) $(5$}

Distributed under a Creative Commons Attribution - NonCommerciall 4.0 International 
Socioeconomic Inequality in Tobacco use in Kenya: A Concentration Analysis

\author{
Hermann Pythagore Pierre Donfouet \\ Corresponding author’s e-mail: hdonfouet@aphrc.org \\ African Population Health Research Centre, \\ P.O. Box: APHRC Campus, 2nd Floor \\ Manga Close, Off Kirawa Road \\ 10787-00100, Nairobi, Kenya \\ Telephone: +254 (20) 4001000 \\ Shukri Mokamed \\ E-mail: smohamed@aphrc.org \\ African Population Health Research Centre, \\ P.O. Box: APHRC Campus, 2nd Floor \\ Manga Close, Off Kirawa Road \\ 10787-00100, Nairobi, Kenya \\ Eric Malin \\ E-mail: Eric.Malin@univ-rennes1.fr \\ CREM, UMR CNRS 6211 \\ University of Rennes 1, France
}

Acknowledgement: This work was presented at the Center of Research in Economics and Management (CREM, CNRS 6211)'s seminar in June 2018 in Rennes. We are grateful for the comments received which help to improve the quality of the paper. The usual disclaimer applies. 


\begin{abstract}
:
Tobacco use is one of the four major risk factors for non-communicable diseases and its effect on health is well documented. Despite several policies adopted to curb tobacco use, African countries are experiencing the highest growth of tobacco use amongst developing countries.
\end{abstract}

There is ample evidence in the literature about the factors influencing tobacco use among adults and youths in Africa. However, in Africa there is yawning evidence gap on the socioeconomic inequalities in tobacco use. This paper attempts to fill this gap by assessing and exploring socioeconomic inequalities in tobacco use in Kenya. Using the theory of fundamental causes, a rich data set-Global Adult Tobacco Survey, and concentration index, we investigate the determinants of tobacco use in Kenya, and whether tobacco use evenly affect the poor and rich. Our results suggest that there is a strong link between tobacco use and socioeconomic inequality. Overall, the poorer households are more affected by tobacco use than richer households and this socioeconomic inequality is more evident among poorer Kenyan men, and poorer Kenyan households living in urban areas. The decomposition of the concentration index indicates that the overall socioeconomic inequality for current tobacco smokers is explained by $40.317 \%$ of the household income. This confinement of tobacco use among the poorest in Kenya could be reduced by increasing taxes on tobacco products.

Keywords: Theory of fundamental causes, tobacco consumption, socioeconomic inequalities, concentration index.

JEL code: D, C2, L66. 


\section{Introduction}

Tobacco use is one of the four major risk factors for non-communicable diseases (NCDs). It is a major public health problem, a preventable cause of disability and premature death. It increases the risk of various cancers (US Department of Health Human Services, 2004), lung diseases, cardiovascular diseases (Boffetta \& Straif, 2009), low birth weight, still birth and is therefore a major contributor to premature death worldwide. In 2015, more than a billion people smoked tobacco globally. About six million preventable deaths occur annually due to tobacco use (WHO., 2015a). Tobacco use also has negative economic effects due to smoking-attributable healthcare costs, productivity loss, and healthcare expenditures on consequent illnesses. Globally, it is estimated that by 2030, tobacco’s annual deaths among adults will be 8.3 million per year (Mathers \& Loncar, 2006). Furthermore, the total economic costs of smoking is substantial, reaching: 2.1\%3.4\% of gross domestic product (GDP) in Australia; 1.3\%-2.2\% of GDP in Canada; and 1.4\%1.6\% in the United States (Lightwood et al., 2000); 3.1\% of national health expenditures in China (Sung et al., 2006); inpatient healthcare cost caused by smoking represented $4.3 \%$ of Vietnam's total health expenditures and 0.22\% of GDP in 2005 (H. Ross et al., 2007); USD 41.56 million in total direct health care and non-health care cost of tobacco-related illnesses in Uganda, USD 11.91 million and USD 73.01 million in total indirect morbidity and mortality costs from the loss of productivity due to tobacco-related illnesses respectively and $0.5 \%$ of GDP and $2.3 \%$ of the national health account in total healthcare cost (Nargis et al., 2017).

Despite the well documented negative impact of smoking on health, there is still scant evidence of studies exploring whether tobacco use evenly affect the poor and rich in sub-Saharan African (SSA) countries. SSA countries face a surge in NCDs and it is predicted that tobacco consumption 
will double in the next 12 to 13 years if concrete policy interventions are not implemented (Baleta, 2010). In 2004, tobacco use was estimated to be responsible for 5\% of NCD-related deaths in Africa (WHO., 2012), while in 2012, 3\% of all deaths among adults aged 30 years and above were attributed to tobacco use in the Africa region (WHO., 2015b). If the current tobacco use trends continue, deaths are expected to increase to 10 million deaths each year, and the majority of these deaths will be occurring in low-and middle-income countries (Roemer et al., 2005; WHO., 2014). However, giving the high level of inequality in SSA countries, there could be large differences and disparities in tobacco use between individuals in some SSA countries.

The theory of fundamental causes (Mackenbach et al., 2017; Phelan \& Link, 2005; Phelan et al., 2004; Phelan et al., 2010) posits that a social position of individuals within a community or country can be a good predictor of poor health, health disparities. The theory is useful in understanding why health disparities still persist even when risk factors which used to affect low-income individuals have been resolved (Willson, 2009), and why individuals socioeconomic position could be a fundamental cause of disparities in health and health behaviors. The theory has been used to investigate inequalities in HIV/AIDS mortality (Rubin et al., 2010), surgical disparities (Qasim, 2016), violence and property crime (Barkan \& Rocque, 2018).

We expand this theory to examine socioeconomic inequalities in risky health-related behaviors such as tobacco use in Kenya. We argue that individuals in the top $20 \%$ of income may have more knowledge about the dangers of smoking and how to avoid it, better access to smoking cessation program and counselling, and could be less likely to smoke than poorer individuals. Hence, in societies with more competition of resources and inequality such as Kenya (Stewart, 2010), individuals with high income seem to have more access to knowledge, healthcare services and take this advantage to avoid any smoking behavior that could be detrimental to their health. Put 
differently, since the richer households have more money, power than the poorer households they could spend more time getting healthy by acquiring more knowledge about the dangers of tobacco use, buying medicines that could help them quit smoking. This can also be explained by the fact that the poor are more present-oriented, less likely to feel personally concerned by anti-tobacco sensitization campaigns (Peretti-Watel et al., 2013). We therefore hypothesize that richer households may be less inclined to tobacco use than poorer households, and this inequality in tobacco use is mainly explained by income inequality.

Our paper contributes to existing literature in many ways. First, the paper updates and contributes to scant evidence in socioeconomic inequality in tobacco use in African countries. Despite several policies adopted to curb tobacco use, African countries are still experiencing the highest growth of tobacco use amongst developing countries. Nowadays, there is an interest on research in gender with a global agenda advocating to reduce gender gap in African countries. Research on gender and tobacco use had been studied extensively (Amos et al., 2011; Kauffman et al., 1997; Legleye et al., 2011; Leventhal et al., 2007; Morrow \& Barraclough, 2010; Prescott et al., 1998; Waldron et al., 1988b; Wang et al., 2005). However, little attention has been given to socioeconomic inequality in tobacco use with respect to gender. Exploring socioeconomic inequality in tobacco use could help policymakers design effective policies that have an inequality in perspective that could decrease the prevalence of tobacco use, and also shrink health inequalities. Second, we provide strong evidence about factors which mostly explain the income-related inequality in tobacco use. Thus, we are able via econometrics tools to provide evidence about the inequalities that generate inequalities in tobacco use. Investigating socioeconomic inequality in tobacco use is not enough since inequalities in tobacco use could be a result of inequalities in income, gender and education. Policymakers could therefore be keen to know the contributions of each of these 
inequalities in observed inequalities in tobacco use. Hence, we examine the relative contribution of each explanatory factor in explaining income-related inequality in smoking and smokeless tobacco in Kenya. Our analysis therefore provide strong empirical evidence on socioeconomic gradients on different types of tobacco use but also on main factor that could explain these socioeconomic gradients on different types of tobacco use.

The objective of the article is to investigate socioeconomic inequality in smoking and smokeless tobacco in Kenya. Results of the study suggest that smoking and smokeless tobacco are more concentrated among the poor. This income-related inequality is more evident among poorer Kenyan men, and poorer Kenyan households living in urban areas. The decomposition of the concentration index indicates that the overall socioeconomic inequality for current tobacco smokers is explained by $40.317 \%$ of the household income.

The paper is structured as follows. Section 2 presents the data and methods while Section 3 outlines the results of the study. Section 4 discusses the findings while Section 5 concludes with some policy recommendations.

\section{Methods}

\subsection{Data}

In 2005, Kenya joined the WHO Framework Convention on Tobacco Control and adopted several policies to control tobacco use such as smoke free places, prohibiting all forms of advertising and promotion of tobacco products, tobacco packaging warning messages. The tobacco control act was finally adopted in 2007 and later challenged by the tobacco manufacturer British American Tobacco Limited. Since then, there is resurgence of studies on tobacco use in Kenya. 
All data used in this study emanate from the 2014 Global Adult Tobacco Survey (GATS). The GATS is a survey conducted in several countries. It aims at monitoring adult tobacco use (smoking and smokeless) and tracking key tobacco control indicators. The 2014 GATS for Kenya is the first of its kinds on tobacco survey asking rich questions on background characteristics, tobacco use, cessation, economic indicators, knowledge, attitudes and perceptions towards tobacco use to a nationally representative household survey of adults aged 15 years and older (KNBS, 2014). Most of the questions asked correspond to the World Health Organization MPOWER strategies which aim at monitoring tobacco use, protecting people from tobacco smoke, offering help to quit tobacco use, warning about the dangers of tobacco, enforcing bans on tobacco advertising, and raising taxes on tobacco.

The survey design is a clustered multistage sampling covering 47 counties in Kenya. Respondents were selected using a three-stage cluster sampling. At the first stage, 192 clusters or enumerations areas were selected while at the second stage, 28 households were selected in each cluster using equal probability systematic sampling method. At the last stage, eligible individuals were randomly selected. Overall, 4408 respondents completed the interview and the overall response rate was $87.1 \%$. The response rate was $85.6 \%, 88.8 \%$ in urban areas and rural areas, respectively (KNBS, 2014). Giving the study design, sampling weights and clustering are used in the univariate analysis, multivariate analysis and concentration index estimates.

In tobacco literature there is a major difference between combusted tobacco/cigarette and smokeless tobacco. The latter is less harmful than combusted tobacco and it refers to tobacco products that are not smoked but used in another form such as sniffing, chewing. In Kenya, smokeless tobacco comprised chewing tobacco, kuber, snuff and betel quid. Combusted tobacco/cigarette is tobacco that is burned during consumption. 
In the current study, our main dependent variable is current tobacco smokers which includes both daily and occasional (less than daily) use of tobacco within the past 30 days. Hence, current tobacco smokers is a binary variable which takes the value one if the respondent currently smokes tobacco on a daily basis or occasional within the past 30 days preceding the survey, and zero otherwise. We also explore the robustness of our findings focusing on daily use of tobacco (binary variable taking the value one if the respondent currently smokes tobacco on a daily basis within the 30 days preceding the survey, and zero otherwise), daily cigarette smokers (this includes respondents who had smoked at least one manufactured or hand-rolled cigarette per day within the 30 days preceding the survey. It is a binary variable which takes one if the respondent currently smokes manufactured cigarettes or hand-rolled cigarettes on a daily basis within the 30 days preceding the survey), daily smokeless tobacco users (binary variable-one if the respondent currently uses smokeless tobacco on a daily basis within the 30 days preceding the survey). Furthermore, we use the notable theory of triadic influence to explain Kenyan adults' tobacco use behaviors. Applying to adults' tobacco use, the theory could be adapted in helping understand the health-related behavior executed by individuals that could be summarized in three levels (see for instance Kabir \& Goh, 2014): individual, neighborhood/family environment and societal levels. The selection of our covariates was therefore guided by theory (Flay et al., 1995; Kabir \& Goh, 2014). We use the gender, age, wealth index and education to capture the individual level. The second level (neighborhood/family environment) could be peer groups, friends, smoking allowed at home, parental influence, place of residence etc. Some of these variables are inexistent in the 2014 GATS for Kenya. Borrowing from the contagion perspective which posits that individuals are influenced by others around them (Crane, 1991; C. E. Ross, 2000), we choose smoking allowed at home. Smoking allowed at home is picked since households are more likely to adopt tobacco 
use if they are more exposed to tobacco in their home, and they could copy the smoking behavior of others. Another variable used is the place of residence since households living in urban setting could be more prone to tobacco use as compared to their counterparts in rural setting since urban setting may have more permissive norm towards tobacco use or it could be more stressful to individuals who will eventually incline to tobacco use in order to relief the stress (Idris et al., 2007; Shohaimi et al., 2003). The third level is the societal factor such as mass media, smoking in public places, knowledge and perceptions about the dangers of tobacco use, easy access, promotion and marketing, social attitudes and norms, enforcement of tobacco control law and policies, etc. Very few of these variables are found in the dataset. Thus, we use the mass media and knowledge about the dangers of tobacco use. All these three levels are interwoven with each other (Flay et al., 1999). It is noteworthy to emphasize that the wealth/income index was constructed using the polychoric principal component analysis (pPCA) on 13 questions on household assets. Applying PCA on binary variable seems inappropriate because the assumption of normality with discrete variable is conceptually unappealing. To circumvent this issue, Kolenikov and Angeles (2009) suggested that there are normal latent distributed continuous variables underlying observed binary variables. The correlation matrix of these latent variable is estimated and a standard PCA is then applied to this matrix. We follow this procedure known as the pPCA and use the first component as the measure of wealth index or socioeconomic status. This was needed to explore the socioeconomic inequality in tobacco use in Kenya. The sample household is then classified into wealth quintiles. Wealth index based on assets is most often used in demographic and health surveys, other settings to analyze poverty and inequalities (Filmer \& Pritchett, 2001; Filmer \& Scott, 2012; Howe et al., 2009; Lindelow, 2006; McKenzie, 2005). 
A Probit model was used to investigate the factors that could influence tobacco use among Kenyan. Table 1 and Table A1 present the different variables for the analysis and household assets used to construct the wealth index, respectively.

\section{[Insert Table 1 about here]}

\subsection{Concentration index}

Concentration index (CI) is a measure of inequality that provides the extent to which a health indicator is concentrated among the disadvantaged or the advantaged respondents in a country, community.

We use conventional methods for estimating the socioeconomic inequality in tobacco use in Kenya. We employ the $C I$ which measures the income-related inequality associated with tobacco use. The calculation of the $C I$ is straightforward. First, respondents are ranked by wealth/income quintiles beginning with the poorest in the population. The concentration curve, $L(s)$, then plots the cumulative percentage of the population ranked by wealth quintiles against their cumulative percentage of tobacco use (O'Donnell et al., 2007). The $C I$ is comprised between [-1, 1], a value of -1 signifies that tobacco use is entirely concentrated in the poorest while a positive higher index value implies that tobacco use tends to be concentrated among richer households. When there is no inequality, the index will be zero. A visual inspection could also be done with the concentration curve. The farther the curve is above the line of equality, the more concentrated tobacco use is among the poor. If tobacco use is concentrated in the lower income groups, $L(s)$ will lie above the diagonal (the 45 degree line). The $C I$ is twice the area between $L(s)$ and the diagonal and it is given by the following formula: 
$C I=\frac{2}{\mu_{T}} \operatorname{cov}\left(T_{i}, r_{i}\right)$,

where $\mu_{T}$ is the mean of tobacco use, $r_{i}$ the fractional rank of the ith individual, and $T_{i}$ is tobacco use. When the variable is binary, we assess the $C I$ following Wagstaff (2005). The problem with binary variable is that the $C I$ is no longer bounded between -1 and +1 , it is rather bounded between $\mu_{T}-1$ and $1-\mu_{T}$ which affects interpretability of the inequality measure and this is impacted by the mean of binary variable $\left(\mu_{T}\right)$. Wagstaff (2005) suggested a normalization by dividing the original $C I$ by one minus the mean of the dependent binary variable. Thus:

$C I_{W}=\frac{C I}{1-\mu_{T}}$

The decomposition of the $C I$ into the underlying determinants which explain the socioeconomic inequality in tobacco use is interesting from policy perspective. It allows the impact of each determinant and its contribution to be estimated. It also provides policymakers with a better understanding of why observed socioeconomic inequality in tobacco use is rampant, and instruments that could be used to curb socioeconomic inequality. We follow Van Doorslaer and Jones (2003), Wagstaff et al. (2003) by disaggregating the $C I$ into contributions of individual factors to income-related tobacco use inequality. If we assume that tobacco use $\left(T_{i}\right)$ can be described as a linear relationship with a vector of covariates $\left(X_{k i}\right)$ affecting tobacco use, the equation could be written as follows: 
$T_{i}=a_{i}+b_{k} X_{k i}+\varepsilon_{i}$,

then the $C I$ can be written as:

$C I=\sum_{k}\left(\frac{b_{k} \bar{x}_{k}}{\mu_{T}}\right) C_{k}+\frac{G C_{\varepsilon}}{\mu_{T}}$,

with $C_{k}$ the concentration index for each covariate which suggest the degree to which the covariate itself varies with respect to income, $b_{k}$ is the coefficient or partial effect for each covariate, $G C_{\varepsilon}$ is the generalized $C I$ for the residual $\left(\varepsilon_{i}\right)$. The term $\frac{b_{k} \bar{x}_{k}}{\mu_{T}}$ is the elasticity of tobacco use with respect to the covariate, and the following term $\left(\frac{b_{k} \bar{x}_{k}}{\mu_{T}}\right) C_{k}$ is the contribution of each covariate to the socioeconomic inequality in tobacco use. The percentage contribution is obtained by dividing the contribution by the overall income-related inequality.

\section{Results}

\subsection{Descriptive results}

Table 2 and Table A2 provide the descriptive results of the study. The overall proportion of current tobacco (daily tobacco) smokers is 7.8\% (6\%) (Table 2), representing $15.075 \%$ (11.597\%) of males and $0.766 \%$ females (0.599\%) (Table A2). Results of the study indicate that current tobacco, daily tobacco and daily cigarettes smoking are statistically and significantly higher with men than females since their respective confidence intervals do not overlap (Table A2). In the same vein, with regards to smokeless tobacco users the overall proportion for the whole country is $3.3 \%$, with 
3.508\% males and 3.189\% females. Table A2 shows that respondents aged between 45 years and 64 years have the highest proportion of current tobacco smokers (14.997\%), daily tobacco smokers (12.684\%), daily cigarette smokers (12.639\%) and daily smokeless tobacco users (7.329\%). Furthermore, results displayed in Table A2 and Figure 1 provide evidence of socioeconomic inequality in tobacco use although it is not monotonic for current tobacco, daily tobacco and daily cigarette smokers. We also report the inter-quintile range ratio (IQRR) which examines the gap between the richest and poorest in terms of tobacco use. It is the ratio of the average tobacco use of the richest $20 \%$ of the respondents in the sample to the average tobacco use of the poorest $20 \%$ of the respondents in the sample) for current tobacco smoking is 0.437 (0.258), implying that the average of the current tobacco (daily tobacco) smoking for the richest respondents is $0.437(0.258)$ times lower than that of the poorest respondents. Concerning smokeless tobacco, the inter-quintile range ratio is 0.148 , indicating that the average smokeless tobacco of the richest respondents is 0.148 times lower than that of the poorest respondents. The proportion of daily tobacco smokeless decreases monotonically from the poorest quintile to the richest quintile (Figure 1).

In Figure 2 and Figure 3, we inspect the socioeconomic inequality in tobacco use with respect to place of residence and gender. Figure 2 shows that socioeconomic inequality in tobacco use is more pronounced in urban areas if tobacco smoking is measured as current tobacco smokers, daily tobacco smokers and daily cigarette smokers. However, daily smokeless tobacco disproportionately affects the poor respondents in urban and rural areas as well. Figure 3 also shows that socioeconomic inequality in tobacco use is not an issue for female respondents but mainly plagued the poor males when we focus on current tobacco smokers, daily tobacco smokers and daily cigarette smokers. A different picture, however, emerges for daily smokeless tobacco users: the poorest females and males are more affected by tobacco use than the richest. 
These results are substantiated when we estimate the $C I$. Results in Table 3 suggest that overall income-related inequality in tobacco use is negative, statistically significant and favors the betteroff irrespective of the measure of tobacco use. This means that inequality in tobacco use is more prevalent among the poor than the wealthy. Our findings also confirm that tobacco use is more concentrated among poor males, urban areas except for daily smokeless tobacco.

We also explore the main brand used by respondents. In Kenya, Sportsman is manufactured by British America Tobacco. It is the most popular brand in Kenya. Supermatch is manufactured by a local tobacco company called Mastermind Tobacco Kenya, the second-largest tobacco company in Kenya. During the last purchase the main brand of cigarettes purchased was Sportsman (55.2\%) followed by Supermatch (22.9\%). Across income quintiles, the percentages for Sportsman are 25.98\%, $13.79 \%, 25.60 \%, 18.65 \%$, and $15.98 \%$ for the poorest, poor, middle-income, rich and richest respondents, respectively. However, results suggest that rich respondents most often consumed expensive brands such as Dunhill Lights: 0\%, 0\%, 0\%, 61.04\%, and 38.96\% for the poorest, poor, middle-income, rich and richest respondents, respectively.

\section{[Insert Table 2, 3 and Figure 1, 2, 3 about here]}

\subsection{Econometric results}

In Table 4, with regards to current tobacco smokers, daily tobacco smokers and daily cigarette smokers, our results suggest that tobacco use is significantly higher among males, poorest and middle-income respondents, less educated respondents, respondents who tolerate smoking at home. Results indicate that being male increase the probability of being current tobacco smokers 
(daily tobacco smokers/daily cigarette smokers) by 0.078 (0.045), and daily smokeless tobacco users by 0.009 . Furthermore, being aged between 45 years and 64 years increased the probability of being current tobacco smokers (daily tobacco smokers) by 0.021 (0.011), but decrease the probability of being daily smokeless tobacco users by 0.008 . Being ranked as the poorest respondents increase the probability of being current tobacco smokers (daily tobacco smokers/daily cigarette smokers) by 0.020 (0.017). With regards to daily smokeless tobacco users, being poorest respondents will increase the probability of using smokeless tobacco daily by 0.09 if we include as covariates only the five income quintiles in the model. But, the income quintiles do not have any statistical significant effect when other covariates are included in the model (See the last column of Table 4). It is noteworthy that respondents who have been exposed to media regarding the dangers of tobacco use are less likely to daily smoke tobacco and cigarettes. Also, respondents who have knowledge about the dangers of tobacco use decrease the probability of using smokeless tobacco daily by 0.011 .

According to our main results, socioeconomic inequality in tobacco use is mainly explained by the direct effect of the income, which accounts for $40.317 \%$ of the CI (sum of all percentage contributions of the wealth index found in Table 5). Since the absolute contribution of the income is negative, this implies if inequality in tobacco use was solely determined by the income, it would favor the better-off. Results also indicate that $21.681 \%$ of the inequality in tobacco use is explained by unobserved heterogeneity. This unexplained source of inequality in tobacco use seem to favor the better-off. Furthermore, Table A3, A4 and A5 present the same findings for daily tobacco smokers, daily cigarette smokers and daily smokeless tobacco, respectively, and the contributions of the residuals seem high. 


\section{[Insert Table 4 and 5 about here]}

\section{Discussions}

Our findings suggest that tobacco use increases with males, less educated individuals. This is in line with other previous evidence (Chockalingam et al., 2013; Giovino et al., 1995; Giovino et al., 2012; Higgins et al., 2015; Waldron, 1991; Waldron et al., 1988a). Several hypotheses could explain this gender differences in the prevalence of tobacco use in Kenya. Among existing hypotheses, it was stated that women are more likely to feel sick during the first use of tobacco, and they are therefore less likely to use tobacco (Kaplan et al., 1990; Silverstein et al., 1980). Social norms and customs in many African societies also discourage women to smoke and this may explain why tobacco use is more prevalent among men than women in Kenya. We also find that less educated respondents are more likely to smoke as compared to more educated respondents. This finding is consistent with existing studies (Gilman et al., 2008; Koning et al., 2015; Sander, 1995). This could be due to the fact that more educated individuals learn and know more about health risks associated to tobacco use more than less educated individuals. But, Maralani (2014) stated that educational disparities in adult smoking is explained by choices made in early adolescence. We also find a "contagion effect” since respondents who allow smoking in their homes are more likely to smoke. This is consistent with Barreto et al. (2013)'s study who found that adolescents living in households with no smoking restrictions had a greater likelihood of being smokers. This is consistent with social contagion theory (Christakis \& Fowler, 2013).

More importantly, results from our concentration indices suggest a significant socioeconomic inequality in tobacco use in Kenya irrespective of how tobacco use is measured. Tobacco use in Kenya is more prevalent among the poor than the wealthy. This socioeconomic inequality is more 
explained by the income. Hence, in Kenya the poor smoke the most and could be more inclined to NCDs since it is well established that smoking is related to NCDs. Our findings are consistent with Thakur et al. (2015) who found evidence of inequality in smoking tobacco in India though this inequality is irrelevant with smokeless tobacco. There is also a statistical evidence of incomerelated inequality in tobacco use among Kenyan males and respondents living in urban areas. All these findings are consistent with our expectations since poverty tends to make poor individuals make bad decisions such as crime, cocaine and could drive unhealthy behaviors such as smoking. Our results could be explained by the fact that wealthier individuals could have more access to many resources that allow them to avoid smoking. This is substantiated by our empirical results. Our results suggest that the poorest respondents [proportion=86.11\%, 95\% confidence intervals $(\mathrm{CI})=84.31,87.91]$ have significantly less knowledge about the dangers of tobacco use as compared to the richest respondents [proportion=95.94\%, 95\% CI= 94.54, 97.34]. In the same vein, the poorest respondents are significantly less informed [proportion=17.11\%, 95\% CI= 15.15, 19.07] via the media about the dangers of cigarettes or smokeless tobacco than the richest respondents [proportion $=58.50 \%, 95 \% \mathrm{CI}=55,61.99$ ]. Furthermore, the fact that tobacco use is more concentrated among poor Kenyan men in urban areas is not surprising since poverty is more pronounced in urban Kenya and mainly concentrated among the poor. Hence, the Kenyan urban poor could be more inclined to tobacco use in order to cope with the hardships and stress in urban areas. Our findings suggest that the concentration of tobacco use in Kenya among the poor should be a policy concern and if policymakers do not take any concrete actions inequalities in health could be enhanced. 


\section{Conclusions}

Our study is the first to explore the income-related inequality in tobacco use in Kenya. Overall, our results demonstrate an increase of inequalities in tobacco use. This inequality is strong among males and Kenyan urban setting. Results of the study suggest that health promotion, interventions and policy aim at curbing smoking in Kenya should focus most on the disadvantaged households. Hence, in order to reduce the prevalence rate of smoking in Kenya, policymakers and NGOs could design health interventions which include inequality perspective. For instance, sensitization campaigns could be increased in areas where the poor live such as slums in urban setting. Health workers such as doctors, nurses and other players such as community health workers could be used to promote non-smoking behaviors among the poor. Another effective tool that could be used is to increase taxation on all tobacco products. In economics, taxation is known as an efficient mechanism to correct market failures and human behaviors (Chaloupka, 1991; Dillén, 1995; Franck et al., 2013; Freebairn, 2010). Taxation of tobacco products could be used as an effective instrument to control tobacco consumption while generating substantial government revenues (WHO, 2011, 2014). This policy could be efficient since it has been found that poor individuals are more responsive to price changes than their wealthy counterparts (Farrelly \& Bray, 1998; Remler, 2004; Townsend et al., 1994). However, the potential effect of price increases on tobacco products in Kenya could be a good avenue for future research. 


\section{References}

Amos, A., Greaves, L., Nichter, M., \& Bloch, M. (2011). Women and tobacco: A call for including gender in tobacco control research, policy and practice. Tobacco Control, 050280, 1-8.

Baleta, A. (2010). Africa’s struggle to be smoke free. Lancet, 375, 107-108.

Barkan, S.E., \& Rocque, M. (2018). Socioeconomic status and racism as fundamental causes of street criminality. Critical Criminology, 1-21.

Barreto, S.M., de Figueiredo, R.C., \& Giatti, L. (2013). Socioeconomic inequalities in youth smoking in Brazil. BMJ Open, 3, 1-7.

Boffetta, P., \& Straif, K. (2009). Use of smokeless tobacco and risk of myocardial infarction and stroke: Systematic review with meta-analysis. BMJ, 339, 1-6.

Chaloupka, F. (1991). Rational addictive behavior and cigarette smoking. Journal of Political Economy, 99, 722-742.

Chockalingam, K., Vedhachalam, C., Rangasamy, S., Sekar, G., Adinarayanan, S., Swaminathan, S., et al. (2013). Prevalence of tobacco use in urban, semi urban and rural areas in and around Chennai city, India. PloS One, 8, e76005.

Christakis, N.A., \& Fowler, J.H. (2013). Social contagion theory: Examining dynamic social networks and human behavior. Statistics in Medicine, 32, 556-577.

Crane, J. (1991). Effects of neighborhoods on dropping out of school and teenage childbearing. The urban underclass, 299.

Dillén, M. (1995). Corrective tax and subsidy policies in economies with Bertrand competition. Journal of Public Economics, 58, 267-282.

Farrelly, M.C., \& Bray, J.W. (1998). Response to increases in cigarette prices by race/ethnicity, income, and age groups-United States, 1976-1993. JAMA, 280, 1979-1980. 
Filmer, D., \& Pritchett, L.H. (2001). Estimating wealth effects without expenditure data-or tears: An application to educational enrollments in states of India. Demography, 38, 115-132.

Filmer, D., \& Scott, K. (2012). Assessing asset indices. Demography, 49, 359-392.

Flay, B.R., Petraitis, J., \& Hu, F.B. (1995). The theory of triadic influence: Preliminary evidence related to alcohol and tobacco use. Alcohol and tobacco: From basic science to clinical practice, 37-56.

Flay, B.R., Petraitis, J., \& Hu, F.B. (1999). Psychosocial risk and protective factors for adolescent tobacco use. Nicotine and Tobacco Research, 1, S59 -S65.

Franck, C., Grandi, S.M., \& Eisenberg, M.J. (2013). Taxing junk food to counter obesity. American Journal of Public Health, 103, 1949-1953.

Freebairn, J. (2010). Special taxation of alcoholic beverages to correct market failures. Economic Papers: A journal of applied economics and policy, 29, 200-214.

Gilman, S.E., Martin, L.T., Abrams, D.B., Kawachi, I., Kubzansky, L., Loucks, E.B., et al. (2008). Educational attainment and cigarette smoking: A causal association? International Journal of Epidemiology, 37, 615-624.

Giovino, G.A., Henningfield, J.E., Tomar, S.L., Escobedo, L.G., \& Slade, J. (1995). Epidemiology of tobacco use and dependence. Epidemiologic reviews, 17, 48-65.

Giovino, G.A., Mirza, S.A., Samet, J.M., Gupta, P.C., Jarvis, M.J., Bhala, N., et al. (2012). Tobacco use in 3 billion individuals from 16 countries: An analysis of nationally representative cross-sectional household surveys. The Lancet, 380, 668-679.

Higgins, S.T., Kurti, A.N., Redner, R., White, T.J., Gaalema, D.E., Roberts, M.E., et al. (2015). A literature review on prevalence of gender differences and intersections with other 
vulnerabilities to tobacco use in the united states, 2004-2014. Preventive medicine, 80, 89100.

Howe, L.D., Hargreaves, J.R., Gabrysch, S., \& Huttly, S.R. (2009). Is the wealth index a proxy for consumption expenditure? A systematic review. Journal of Epidemiology \& Community Health, jech. 2009.088021.

Idris, B.I., Giskes, K., Borrell, C., Benach, J., Costa, G., Federico, B., et al. (2007). Higher smoking prevalence in urban compared to non-urban areas: Time trends in six European countries. Health \& place, 13, 702-712.

Kabir, M., \& Goh, K.-L. (2014). Determinants of tobacco use among students aged 13-15 years in Nepal and Sri Lanka: Results from the global youth tobacco survey, 2007. Health Education Journal, 73, 51-61.

Kaplan, M., Carriker, L., \& Waldron, I. (1990). Gender differences in tobacco use in Kenya. Social science \& medicine, 30, 305-310.

Kauffman, S.E., Silver, P., \& Poulin, J. (1997). Gender differences in attitudes toward alcohol, tobacco, and other drugs. Social Work, 42, 231-241.

KNBS. (2014). Global adult tobacco survey. Kenya report 2014. Kenya: Kenya National Bureau of Statistics.

Kolenikov, S., \& Angeles, G. (2009). Socioeconomic status measurement with discrete proxy variables: Is principal component analysis a reliable answer? Review of Income and Wealth, 55, 128-165.

Koning, P., Webbink, D., \& Martin, N.G. (2015). The effect of education on smoking behavior: New evidence from smoking durations of a sample of twins. Empirical Economics, 48, 1479-1497. 
Legleye, S., Khlat, M., Beck, F., \& Peretti-Watel, P. (2011). Widening inequalities in smoking initiation and cessation patterns: A cohort and gender analysis in France. Drug \& Alcohol Dependence, 117, 233-241.

Leventhal, A.M., Waters, A.J., Boyd, S., Moolchan, E.T., Lerman, C., \& Pickworth, W.B. (2007). Gender differences in acute tobacco withdrawal: Effects on subjective, cognitive, and physiological measures. Experimental and clinical psychopharmacology, 15, 21.

Lightwood, J., Collins, D., Lapsley, H., \& Novotny, T.E. (2000). Estimating the costs of tobacco use In P. Jha, \& F.J. Chaloupka (Eds.), Tobacco control in developing countries. Oxford: Oxford University Press.

Lindelow, M. (2006). Sometimes more equal than others: How health inequalities depend on the choice of welfare indicator. Health Economics, 15, 263-279.

Mackenbach, J.P., Looman, C.W., Artnik, B., Bopp, M., Deboosere, P., Dibben, C., et al. (2017). 'Fundamental causes' of inequalities in mortality: An empirical test of the theory in 20 European populations. Sociology of health \& illness, 39, 1117-1133.

Maralani, V. (2014). Understanding the links between education and smoking. Social science research, 48, 20-34.

Mathers, C.D., \& Loncar, D. (2006). Projections of global mortality and burden of disease from 2002 to 2030. PloS Medicine, 3, 2011-2030.

McKenzie, D.J. (2005). Measuring inequality with asset indicators. Journal of Population Economics, 18, 229-260.

Morrow, M., \& Barraclough, S. (2010). Gender equity and tobacco control: Bringing masculinity into focus. Global health promotion, 17, 21-28. 
Nargis, N., Nyamurungi, K., Baine, S.O., \& Kadobera, D. (2017). The health cost of tobacco use in uganda. Health Policy and Planning, 32, 1153-1160.

O'Donnell, O., van Doorslaer, E., Wagstaff, A., \& Lindelow, M. (2007). Analyzing health equity using household survey data: A guide to techniques and their implementation. Washington: The World Bank.

Peretti-Watel, P., L’Haridon, O., \& Seror, V. (2013). Time preferences, socioeconomic status and smokers’ behaviour, attitudes and risk awareness. The European Journal of Public Health, 23, 783-788.

Phelan, J.C., \& Link, B.G. (2005). Controlling disease and creating disparities: A fundamental cause perspective. The Journals of Gerontology Series B: Psychological Sciences and Social Sciences, 60, S27-S33.

Phelan, J.C., Link, B.G., Diez-Roux, A., Kawachi, I., \& Levin, B. (2004). “Fundamental causes” of social inequalities in mortality: A test of the theory. Journal of Health and Social Behavior, 45, 265-285.

Phelan, J.C., Link, B.G., \& Tehranifar, P. (2010). Social conditions as fundamental causes of health inequalities: Theory, evidence, and policy implications. Journal of Health and Social Behavior, 51, S28-S40.

Prescott, E., Osler, M., Anderson, P.K., Hein, H.O., Borch-Johnsen, K., Lange, P., et al. (1998). Mortality in women and men in relation to smoking. International Journal of Epidemiology, 27, 27-32.

Qasim, A. (2016). Using the theory of fundamental causes to show the potential effects of socioeconomic status on surgical outcomes. Journal of Health Disparities Research and Practice, 9, 8. 
Remler, D.K. (2004). Poor smokers, poor quitters, and cigarette tax regressivity. American Journal of Public Health, 94, 225-229.

Roemer, R., Taylor, A., \& Lariviere, J. (2005). Origins of the WHO framework convention on tobacco control. American Journal of Public Health, 95, 936-938.

Ross, C.E. (2000). Walking, exercising, and smoking: Does neighborhood matter? Social science \& medicine, 51, 265-274.

Ross, H., Trung, D.V., \& Phu, V.X. (2007). The costs of smoking in Vietnam: The case of inpatient care. Tobacco Control, 16, 405-409.

Rubin, M.S., Colen, C.G., \& Link, B.G. (2010). Examination of inequalities in HIV/aids mortality in the united states from a fundamental cause perspective. American Journal of Public Health, 100, 1053-1059.

Sander, W. (1995). Schooling and quitting smoking. The Review of Economics and Statistics, 191199.

Shohaimi, S., Luben, R., Wareham, N., Day, N., Bingham, S., Welch, A., et al. (2003). Residential area deprivation predicts smoking habit independently of individual educational level and occupational social class. A cross sectional study in the norfolk cohort of the european investigation into cancer (epic-norfolk). Journal of Epidemiology \& Community Health, 57, 270-276.

Silverstein, B., Feld, S., \& Kozlowski, L.T. (1980). The availability of low-nicotine cigarettes as a cause of cigarette smoking among teenage females. Journal of Health and Social Behavior, 383-388.

Stewart, F. (2010). Horizontal inequalities in kenya and the political disturbances of 2008: Some implications for aid policy. Conflict, Security \& Development, 10, 133-159. 
Sung, H.Y., Wang, L., Jin, S., \& Jiang, Y. (2006). Economic burden of smoking in china, 2000. Tobacco Control, 15, i5-i11.

Thakur, J., Prinja, S., Bhatnagar, N., Rana, S.K., Sinha, D.N., \& Singh, P.K. (2015). Widespread inequalities in smoking \& smokeless tobacco consumption across wealth quintiles in states of India: Need for targeted interventions. The Indian journal of medical research, 141, 789.

Townsend, J., Roderick, P., \& Cooper, J. (1994). Cigarette smoking by socioeconomic group, sex, and age: Effects of price, income, and health publicity. BMJ, 309, 923-927.

US Department of Health Human Services (2004). The health consequences of smoking: A report of the surgeon general. Atlanta, GA: US Department of Health and Human Services, Centers for Disease Control and Prevention, National Center for Chronic Disease Prevention and Health Promotion, Office on Smoking and Health, 62.

Van Doorslaer, E., \& Jones, A.M. (2003). Inequalities in self-reported health: Validation of a new approach to measurement. Journal of Health Economics, 22, 61-87.

Wagstaff, A. (2005). The bounds of the concentration index when the variable of interest is binary, with an application to immunization inequality. Health Economics, 14, 429-432.

Wagstaff, A., Van Doorslaer, E., \& Watanabe, N. (2003). On decomposing the causes of health sector inequalities with an application to malnutrition inequalities in Vietnam. Journal of Econometrics, 112, 207-223.

Waldron, I. (1991). Patterns and causes of gender differences in smoking. Social science \& medicine, 32, 989-1005.

Waldron, I., Bratelli, G., Carriker, L., Sung, W.-C., Vogeli, C., \& Waldman, E. (1988b). Gender differences in tobacco use in Africa, Asia, the Pacific, and Latin America. Social science \& medicine, 27, 1269-1275. 
Wang, Y., Browne, D.C., Storr, C.L., \& Wagner, F.A. (2005). Gender and the tobacco-depression relationship: A sample of african american college students at a historically black college or university (hbcu). Addictive behaviors, 30, 1437-1441.

WHO (2011). Tobacco tax administration. Geneva: World Health Organization.

WHO (2014). Raising tax on tobacco: What you need to know. Geneva: World Health Organization.

WHO (2012). WHO global report on mortality attributable to tobacco. Geneva: World Health Organization.

WHO (2014). Global status report on noncommunicable diseases 2014. Geneva: World Health Organization.

WHO (2015a). Global report on trends in tobacco smoking 2000-2025. Geneva: World Health Organization.

WHO (2015b). The WHO framework convention on tobacco control: 10 years of implementation in the african region. Geneva: World Health Organization.

Willson, A.E. (2009). Fundamental causes' of health disparities: A comparative analysis of Canada and the United States. International Sociology, 24, 93-113. 
Figure 1: Distribution of the smoking and smokeless tobacco across income quintiles
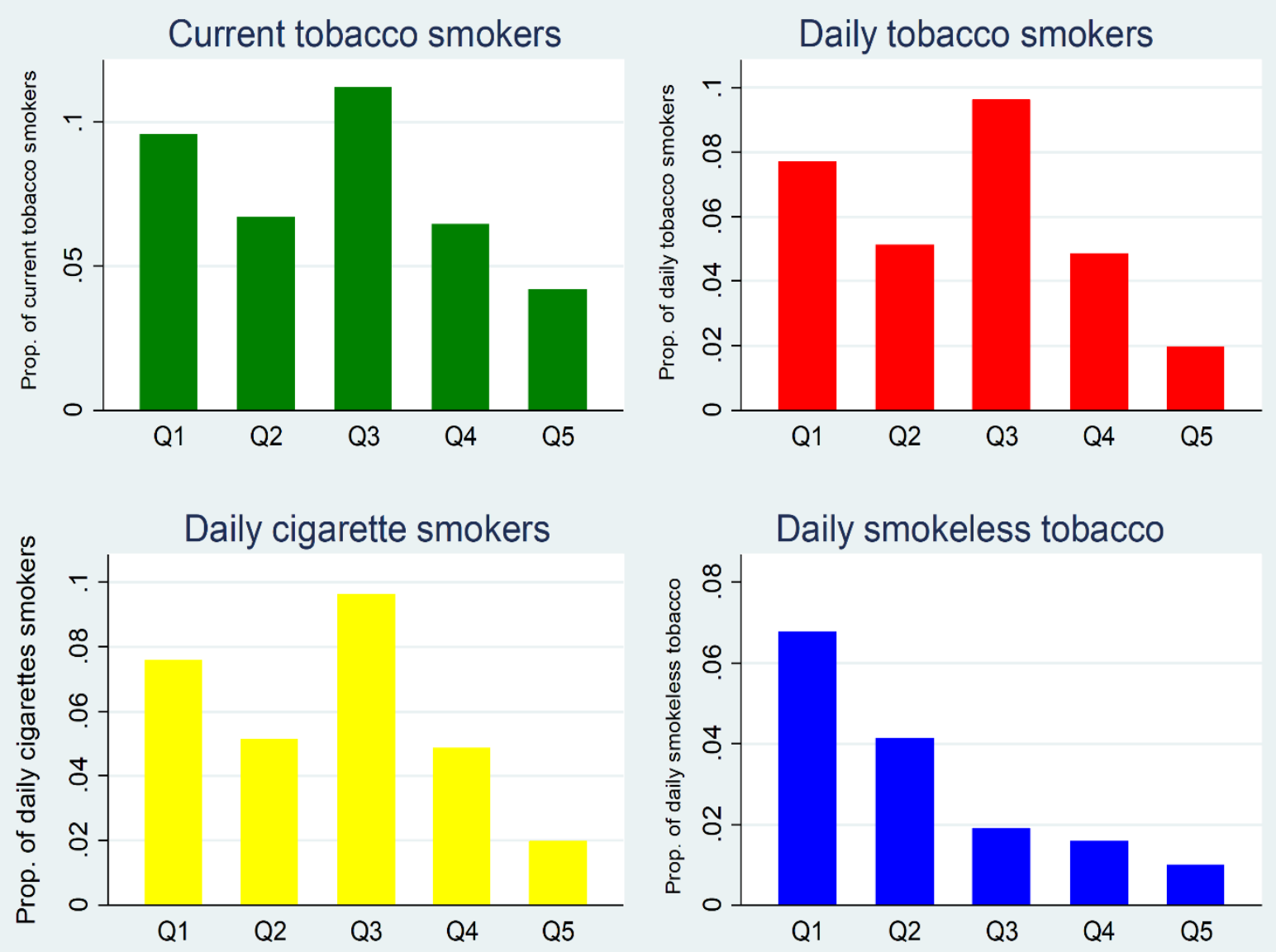
Figure 2: Distribution of the smoking and smokeless tobacco by residence across income quintiles
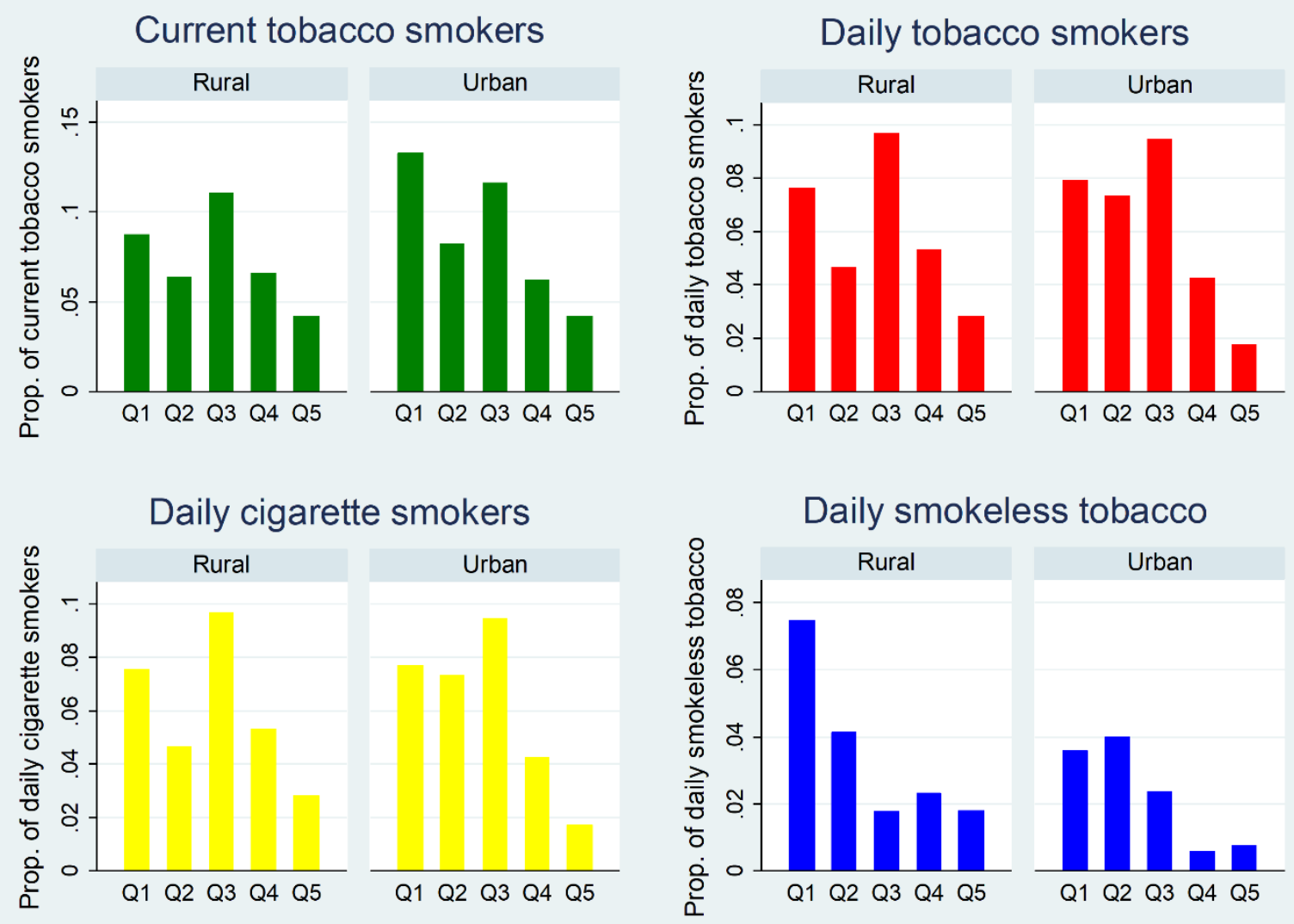
Figure 3: Distribution of the smoking and smokeless tobacco by gender across income quintiles
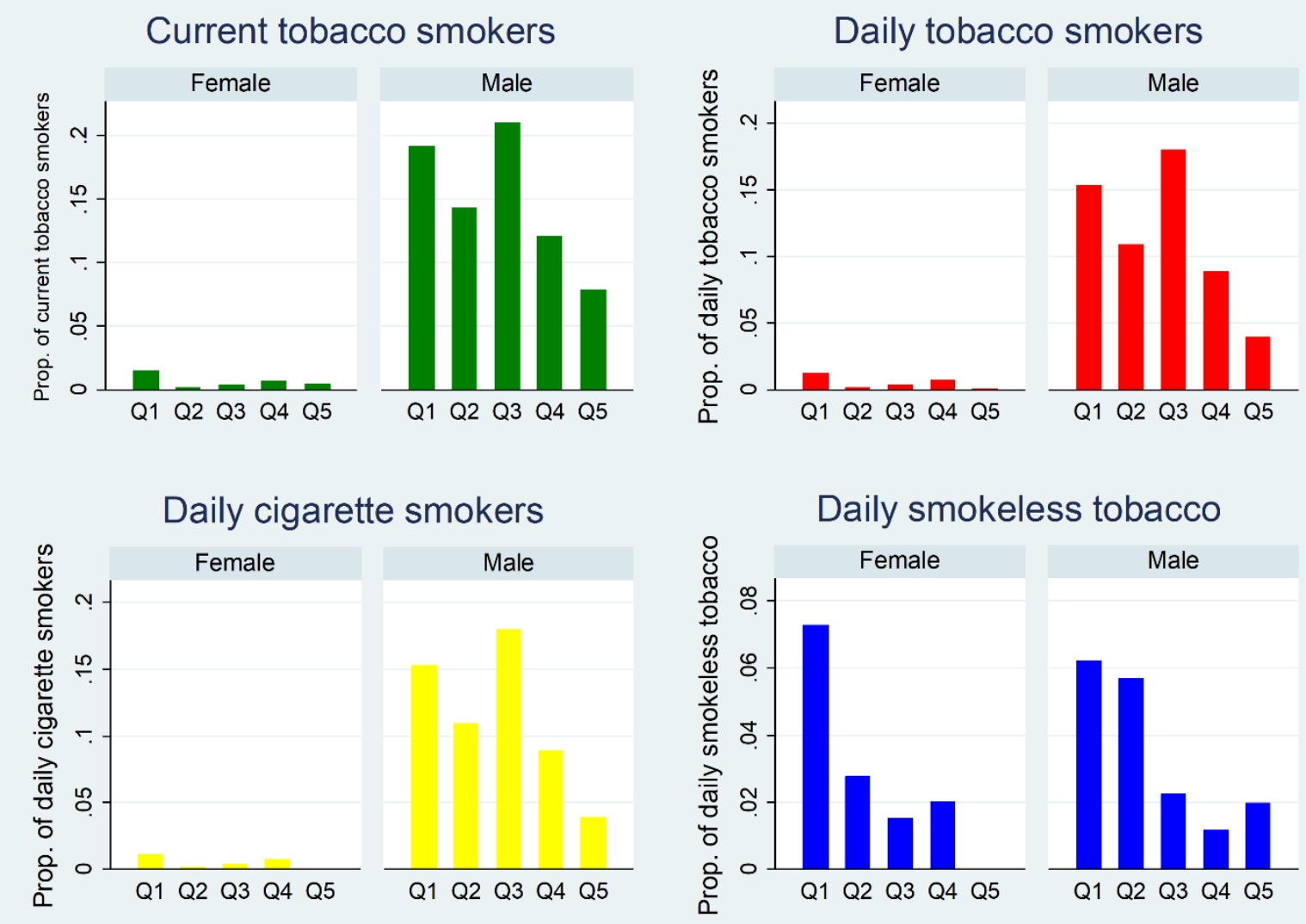
Table 1: Definition of variables

\begin{tabular}{|c|c|}
\hline Variables & Definition \\
\hline \multicolumn{2}{|r|}{ Dependent variables } \\
\hline Current tobacco smokers & $\begin{array}{l}1 \text { if the respondent currently smokes tobacco on a daily basis or less than } \\
\text { a daily within the past } 30 \text { days; } 0 \text { otherwise. }\end{array}$ \\
\hline Daily tobacco smokers & $\begin{array}{l}1 \text { if the respondent currently smokes tobacco on a daily basis within the } \\
\text { past } 30 \text { days; } 0 \text { otherwise. }\end{array}$ \\
\hline Daily cigarette smokers & $\begin{array}{l}1 \text { if the respondent currently smokes manufactured cigarettes or hand- } \\
\text { rolled cigarettes on a daily basis within the past } 30 \text { days; } 0 \text { otherwise. }\end{array}$ \\
\hline $\begin{array}{l}\text { Daily smokeless tobacco } \\
\text { users }\end{array}$ & $\begin{array}{l}1 \text { if the respondent currently uses smokeless tobacco on a daily basis } \\
\text { within the past } 30 \text { days; and } 0 \text { otherwise. }\end{array}$ \\
\hline \multicolumn{2}{|r|}{ Independent variables } \\
\hline Gender & 1 if male; 0 otherwise. \\
\hline Age1 (years), 15-24 & $\begin{array}{l}\text { Age of the respondent, } 1 \text { if the respondent belongs to the age range 15- } \\
24 ; 0 \text { otherwise. }\end{array}$ \\
\hline Age2 (years), 25-44 & $\begin{array}{l}\text { Age of the respondent, } 1 \text { if the respondent belongs to the age range } 25 \text { - } \\
44 ; 0 \text { otherwise. }\end{array}$ \\
\hline Age3 (years), 45-64 & $\begin{array}{l}\text { Age of the respondent, } 1 \text { if the respondent belongs to the age range } 45- \\
64 ; 0 \text { otherwise. }\end{array}$ \\
\hline More than 65 years & $\begin{array}{l}\text { Age of the respondent, } 1 \text { if the respondent has more than } 65 \text { years; } 0 \\
\text { otherwise. }\end{array}$ \\
\hline Wealth-Q1 & 1if the respondent belongs to the first income quintile; 0 otherwise. \\
\hline Wealth-Q2 & 1if the respondent belongs to the second income quintile; 0 otherwise. \\
\hline Weal & 1if the respondent belongs to the third income quintile; 0 otherwise. \\
\hline Wealth-Q4 & 1if the respondent belongs to the fourth income quintile; 0 otherwise. \\
\hline Wealth-Q5 & 1if the respondent belongs to the fifth income quintile; 0 otherwise. \\
\hline No formal schooling & 1 if the respondent has no formal schooling; 0 otherwise. \\
\hline lary school & 1 if the respondent has not completed primary school; 0 otherwise. \\
\hline Primary school completed & 1 if the respondent has completed primary school; 0 otherwise. \\
\hline Less than & 1 if the respondent has not completed secondary school; 0 otherwise. \\
\hline $\begin{array}{l}\text { More than secondary } \\
\text { completed }\end{array}$ & $\begin{array}{l}1 \text { if the respondent has more than completed secondary school; } 0 \\
\text { otherwise. }\end{array}$ \\
\hline Urban & 1 if the respondent resides in urban area; 0 otherwise. \\
\hline Media & $\begin{array}{l}1 \text { if the respondent has noticed information in newspapers/magazines } \\
\text { about the dangers of use or that encourages quitting cigarettes/smokeless } \\
\text { tobacco, or has seen any information on TV about the dangers of use or } \\
\text { that encourages quitting smokeless cigarettes/tobacco; } 0 \text { otherwise. }\end{array}$ \\
\hline Knowledge & $\begin{array}{l}1 \text { if the respondent has knowledge that tobacco use cause serious } \\
\text { illness; } 0 \text { otherwise. }\end{array}$ \\
\hline Smoking allowed at home & $\begin{array}{l}1 \text { if the respondent has flexible rule-smoking is allowed inside his/her } \\
\text { home. }\end{array}$ \\
\hline
\end{tabular}


Table 2: Summary statistics of the variables

\begin{tabular}{|c|c|c|c|c|}
\hline Variables & Mean & Std. Dev. & Min & Max \\
\hline Current tobacco smokers & 0.078 & 0.267 & 0 & 1 \\
\hline Daily tobacco smokers & 0.060 & 0.237 & 0 & 1 \\
\hline Daily cigarette smokers & 0.059 & 0.236 & 0 & 1 \\
\hline Daily smokeless tobacco users & 0.033 & 0.179 & 0 & 1 \\
\hline Gender & 0.488 & 0.500 & 0 & 1 \\
\hline Age1 (years), 15-24 & 0.361 & 0.231 & 0 & 1 \\
\hline Age2 (years), 25-44 & 0.417 & 0.243 & 0 & 1 \\
\hline Age3 (years), 45-64 & 0.161 & 0.135 & 0 & 1 \\
\hline More than 65 years & 0.060 & 0.057 & 0 & 1 \\
\hline Wealth-Q1 & 0.270 & 0.197 & 0 & 1 \\
\hline Wealth-Q2 & 0.161 & 0.135 & 0 & 1 \\
\hline Wealth-Q3 & 0.179 & 0.147 & 0 & 1 \\
\hline Wealth-Q4 & 0.191 & 0.154 & 0 & 1 \\
\hline Wealth-Q5 & 0.197 & 0.158 & 0 & 1 \\
\hline No formal education & 0.137 & 0.344 & 0 & 1 \\
\hline Less than primary school completed & 0.246 & 0.431 & 0 & 1 \\
\hline Primary school completed & 0.213 & 0.409 & 0 & 1 \\
\hline Less than secondary completed & 0.116 & 0.320 & 0 & 1 \\
\hline More than secondary completed & 0.288 & 0.453 & 0 & 1 \\
\hline Urban & 0.350 & 0.477 & 0 & 1 \\
\hline Media & 0.356 & 0.479 & 0 & 1 \\
\hline Knowledge & 0.927 & 0.260 & 0 & 1 \\
\hline Smoking allowed at home & 0.094 & 0.292 & 0 & 1 \\
\hline
\end{tabular}

Table 3: Concentration index, Wagstaff index

\begin{tabular}{llllll}
\hline Dependent variables & \multicolumn{4}{c}{ Concentration index-Wagstaff index } \\
\hline & \multicolumn{2}{c}{ Gender } & \multicolumn{2}{c}{ Residence } \\
\hline Current tobacco smokers & -0.148 & -0.183 & -0.269 & -0.277 & -0.067 \\
& $(0.056)^{* * *}$ & $(0.058)^{* * *}$ & $(0.200)$ & $(0.079)^{* * *}$ & $(0.065)$ \\
Daily tobacco smokers & -0.189 & -0.223 & -0.344 & -0.362 & -0.074 \\
& $(0.062)^{* * *}$ & $(0.066)^{* * *}$ & $(0.234)$ & $(0.067)^{* * *}$ & $(0.069)$ \\
Daily cigarette smokers & -0.187 & -0.222 & -0.325 & -0.358 & -0.072 \\
& $(0.063)^{* * *}$ & $(0.066)^{* * *}$ & $(0.241)$ & $(0.067)^{* * *}$ & $(0.070)$ \\
Daily smokeless tobacco & -0.447 & -0.345 & -0.558 & -0.384 & -0.385 \\
users & $(0.119)^{* * *}$ & $(0.130)^{* *}$ & $(0.149)^{* * *}$ & $(0.219)^{*}$ & $(0.126)^{* * *}$ \\
\hline
\end{tabular}

Notes: Sampling weights and clustering are used to account for sampling design of the survey. Standard errors in parentheses. ${ }^{*} p<0.10,{ }^{* *} p<0.05,{ }^{* * *} p<0.01$. Negative values of the concentration index mean that tobacco use is more concentrated among the poor. 
Table 4: Marginal effects of determinants of smoking, Probit model

\begin{tabular}{|c|c|c|c|c|}
\hline Variables & $\begin{array}{l}\text { Current } \\
\text { tobacco } \\
\text { smokers } \\
\end{array}$ & $\begin{array}{c}\text { Daily } \\
\text { tobacco } \\
\text { smokers } \\
\end{array}$ & $\begin{array}{c}\text { Daily } \\
\text { cigarette } \\
\text { smokers }\end{array}$ & $\begin{array}{c}\text { Daily } \\
\text { smokeless } \\
\text { tobacco users }\end{array}$ \\
\hline Gender & $\begin{array}{c}0.078^{* * *} \\
(0.012)\end{array}$ & $\begin{array}{c}0.045^{* * *} \\
(0.009)\end{array}$ & $\begin{array}{c}0.045^{* * *} \\
(0.009)\end{array}$ & $\begin{array}{l}0.009^{* *} \\
(0.004)\end{array}$ \\
\hline Age1 (years), $15-24^{(a)}$ & $\begin{array}{c}-0.037^{* * *} \\
(0.009)\end{array}$ & $\begin{array}{c}-0.027^{* * *} \\
(0.007)\end{array}$ & $\begin{array}{c}-0.025^{* * *} \\
(0.007)\end{array}$ & $\begin{array}{c}-0.030^{* * *} \\
(0.008)\end{array}$ \\
\hline Age2 (years), 25-44 & $\begin{array}{c}0.007 \\
(0.009)\end{array}$ & $\begin{array}{c}0.002 \\
(0.005)\end{array}$ & $\begin{array}{c}0.003 \\
(0.005)\end{array}$ & $\begin{array}{c}-0.019^{* * * *} \\
(0.006)\end{array}$ \\
\hline Age3 (years), 45-64 & $\begin{array}{l}0.021^{* *} \\
(0.010)\end{array}$ & $\begin{array}{l}0.011^{*} \\
(0.006)\end{array}$ & $\begin{array}{l}0.012^{*} \\
(0.007)\end{array}$ & $\begin{array}{l}-0.008^{*} \\
(0.005)\end{array}$ \\
\hline Wealth-Q1 ${ }^{(\mathrm{b})}$ & $\begin{array}{l}0.020^{* *} \\
(0.009)\end{array}$ & $\begin{array}{l}0.017^{* *} \\
(0.007)\end{array}$ & $\begin{array}{l}0.017^{* *} \\
(0.007)\end{array}$ & $\begin{array}{c}0.001 \\
(0.008)\end{array}$ \\
\hline Wealth-Q2 & $\begin{array}{c}0.006 \\
(0.011)\end{array}$ & $\begin{array}{c}0.008 \\
(0.008)\end{array}$ & $\begin{array}{c}0.008 \\
(0.008)\end{array}$ & $\begin{array}{c}0.005 \\
(0.011)\end{array}$ \\
\hline Wealth-Q3 & $\begin{array}{l}0.018^{* * *} \\
(0.009)\end{array}$ & $\begin{array}{l}0.018^{* *} \\
(0.007)\end{array}$ & $\begin{array}{l}0.017^{* *} \\
(0.007)\end{array}$ & $\begin{array}{l}-0.006 \\
(0.007)\end{array}$ \\
\hline Wealth-Q4 & $\begin{array}{c}0.006 \\
(0.010)\end{array}$ & $\begin{array}{c}0.009 \\
(0.007)\end{array}$ & $\begin{array}{c}0.009 \\
(0.007)\end{array}$ & $\begin{array}{l}-0.003 \\
(0.007)\end{array}$ \\
\hline No formal education ${ }^{(\mathrm{c})}$ & $\begin{array}{l}-0.010 \\
(0.010)\end{array}$ & $\begin{array}{l}-0.006 \\
(0.006)\end{array}$ & $\begin{array}{l}-0.006 \\
(0.006)\end{array}$ & $\begin{array}{c}0.031^{* * *} \\
(0.011)\end{array}$ \\
\hline Less than primary school completed & $\begin{array}{l}0.016^{* *} \\
(0.008)\end{array}$ & $\begin{array}{c}0.006^{*} \\
(0.003)\end{array}$ & $\begin{array}{l}0.006^{*} \\
(0.003)\end{array}$ & $\begin{array}{c}0.011 \\
(0.009)\end{array}$ \\
\hline Primary school completed & $\begin{array}{c}0.010 \\
(0.007)\end{array}$ & $\begin{array}{c}0.006 \\
(0.005)\end{array}$ & $\begin{array}{c}0.006 \\
(0.005)\end{array}$ & $\begin{array}{c}0.006 \\
(0.011)\end{array}$ \\
\hline Less than secondary completed & $\begin{array}{l}-0.006 \\
(0.009)\end{array}$ & $\begin{array}{l}-0.004 \\
(0.006)\end{array}$ & $\begin{array}{l}-0.004 \\
(0.006)\end{array}$ & $\begin{array}{c}0.009 \\
(0.013)\end{array}$ \\
\hline Urban & $\begin{array}{c}0.002 \\
(0.006)\end{array}$ & $\begin{array}{l}-0.004 \\
(0.004)\end{array}$ & $\begin{array}{l}-0.004 \\
(0.004)\end{array}$ & $\begin{array}{l}-0.005 \\
(0.005)\end{array}$ \\
\hline Media & $\begin{array}{l}-0.009 \\
(0.006)\end{array}$ & $\begin{array}{l}-0.008^{*} \\
(0.004)\end{array}$ & $\begin{array}{l}-0.008^{*} \\
(0.004)\end{array}$ & $\begin{array}{l}-0.004 \\
(0.005)\end{array}$ \\
\hline Knowledge & $\begin{array}{l}-0.017 \\
(0.011)\end{array}$ & $\begin{array}{l}-0.006 \\
(0.006)\end{array}$ & $\begin{array}{l}-0.005 \\
(0.006)\end{array}$ & $\begin{array}{c}-0.011^{* *} \\
(0.005)\end{array}$ \\
\hline Smoking allowed at home & $\begin{array}{c}0.045^{* * *} \\
(0.010)\end{array}$ & $\begin{array}{c}0.030^{* * *} \\
(0.008)\end{array}$ & $\begin{array}{c}0.029^{* * *} \\
(0.007)\end{array}$ & $\begin{array}{c}0.016^{* * *} \\
(0.005)\end{array}$ \\
\hline Observations & 4407 & 4407 & 4407 & 4407 \\
\hline
\end{tabular}

Notes: Standard errors in parentheses. ${ }^{*} p<0.10,{ }^{* *} p<0.05,{ }^{* * *} p<0.01$. (a) The base group for age is more than 65 years. (b) The reference group for the income quintile is the fifth income quintile (highest income quintile). (c) The reference group for education is more than secondary completed. The model is estimated with the Probit since the dependent variables are binary. Sampling weights and clustering are used to account for sampling design of the survey. 
Table 5: Decomposition of the concentration index, current tobacco smokers

\begin{tabular}{lcccc}
\hline Variables & Elasticity & $\begin{array}{l}\text { Concentration } \\
\text { index }\end{array}$ & $\begin{array}{l}\text { Contribution } \\
\text { to } \mathbf{C}_{\mathbf{K}}=\mathbf{- 0 . 1 4 8}\end{array}$ & $\begin{array}{l}\text { Percentage } \\
\text { contribution }\end{array}$ \\
\hline Gender & 0.488 & 0.045 & 0.022 & -14.819 \\
Age1 (years), 15-24 & -0.171 & 0.006 & -0.001 & 0.660 \\
Age2 (years), 25-44 & 0.037 & 0.081 & 0.003 & -2.038 \\
Age3 (years), 45-64 & 0.043 & -0.065 & -0.003 & 1.892 \\
Wealth-Q1 & 0.069 & -0.920 & -0.064 & 43.035 \\
Wealth-Q2 & 0.012 & -0.427 & -0.005 & 3.575 \\
Wealth-Q3 & 0.041 & 0.033 & 0.001 & -0.919 \\
Wealth-Q4 & 0.015 & 0.541 & 0.008 & -5.374 \\
No formal education & -0.018 & -0.575 & 0.010 & -6.826 \\
Less than primary school completed & 0.050 & -0.304 & -0.015 & 10.380 \\
Primary school completed & 0.027 & -0.002 & -0.0001 & 0.044 \\
Less than secondary completed & -0.009 & 0.085 & -0.001 & 0.511 \\
Urban & 0.009 & 0.532 & 0.005 & -3.225 \\
Media & -0.041 & 0.395 & -0.016 & 10.950 \\
Knowledge & -0.202 & 0.296 & -0.060 & 40.473 \\
Smoking allowed at home & 0.054 & -0.180 & -0.010 & 6.580 \\
Residual & & & -0.032 & 21.681 \\
Total & & & $\mathbf{- 0 . 1 4 8}$ & $\mathbf{1 0 0 . 0 0 0}$ \\
\hline
\end{tabular}




\section{Appendix: Tables}

Table A1: Household assets used to construct the income quintiles

\begin{tabular}{lc}
\hline Assets variable & Weighted proportion \\
\hline Respondent has electricity & 28.78 \\
Respondent has flush toilet & 12.93 \\
Respondent has fixed telephone & 1.18 \\
Respondent has cellphone & 79.69 \\
Respondent has TV & 30.25 \\
Respondent has radio & 73.24 \\
Respondent has refrigerator & 7.80 \\
Respondent has car & 7.80 \\
Respondent has flush scooter/motorcycle & 8.82 \\
Respondent has washing machine & 1.44 \\
Respondent has clock/watch & 37.70 \\
Respondent has bicycle & 24.05 \\
Respondent has computer & 7.79 \\
\hline
\end{tabular}

Notes: For the 13 items, respondent was given three choices: Yes, No and Don't know. Applying pPCA the first eigenvalue is 6.969 and the proportion of variance explained by the first component is 0.536 . 
Table A2: Univariate analysis

$\begin{array}{llll}\text { Current tobacco smokers } & \text { Daily tobacco smokers } & \text { Daily cigarette smokers } & \text { Daily smokeless }\end{array}$

\section{tobacco users}

\begin{tabular}{|c|c|c|c|c|}
\hline Variables & Percentage [95\% CI] & Percentage [95\% CI] & Percentage [95\% CI] & Percentage $[95 \% \mathrm{CI}]$ \\
\hline Male & $15.075[13.54,16.62]$ & $11.597[10.219,12.975]$ & $11.5785[10.202,12.955]$ & $3.508[2.716,4.299]$ \\
\hline Female & $0.766 \quad[0.412,1.120]$ & $0.599[0.285,0.912]$ & $0.561[0.258,0.864]$ & $3.189[2.475,3.903]$ \\
\hline Age1 (years), 15-24 & $2.174 \quad[1.275,3.074]$ & $1.305[0.605,2.005]$ & $1.305[0.605,2.005]$ & $0.790[0.244,1.337]$ \\
\hline Age2 (years), 25-44 & {$[8.537,11.023]$} & $7.268[6.182,8.355]$ & $7.268[6.182,8.355]$ & $2.192[1.579,2.805]$ \\
\hline Age3 (years), 45-64 & $14.997[12.558,17.437]$ & $12.684[10.409,14.958]$ & $12.639[10.368,14.910]$ & $7.329[5.548,9.110]$ \\
\hline More than 65 years & $7.829 \quad[5.117,10.542]$ & $6.937[4.372,9.503]$ & $6.581[4.078,9.085]$ & $15.909[12.216,19.602]$ \\
\hline Wealth-Q1 & $9.587 \quad[8.054,11.121]$ & $7.697[6.308,9.085]$ & $7.590[6.211,8.969]$ & $6.785[5.475,8.095]$ \\
\hline Wealth-Q2 & $6.702[4.761,8.643]$ & $5.131[3.419,6.844]$ & $5.131[3.419,6.844]$ & $4.119[2.577,5.662]$ \\
\hline Wealth-Q3 & $11.215[9.003,13.427]$ & $9.632[7.564,11.701]$ & $9.632[7.564,11.701]$ & $1.901[0.944,2.858]$ \\
\hline Wealth-Q4 & $6.468[4.765,8.172]$ & $4.873[3.382,6.365]$ & $4.873[3.381,6.365]$ & $1.594[0.727,2.462]$ \\
\hline Wealth-Q5 & $4.187[2.767,5.607]$ & $1.989[0.999,2.979]$ & $1.989[0.999,2.979]$ & $1.008[0.300,1.716]$ \\
\hline No formal education & $6.006[4.494,7.518]$ & $5.459[4.013,6.905]$ & $5.316[3.889,6.7443]$ & $15.512[13.208,17.816]$ \\
\hline Less than primary school completed & $11.143[9.155,13.129]$ & $8.527[6.764,10.291]$ & $8.489[6.729,10.249]$ & $2.533[1.541,3.526]$ \\
\hline Primary school completed & $8.816[6.954,10.679]$ & $7.128[5.438,8.818]$ & $7.128[5.438,8.818]$ & $1.129[0.435,1.822]$ \\
\hline Less than secondary completed & $5.087[2.938,7.235]$ & $3.798[1.929,5.667]$ & $3.798[1.929,5.667]$ & $1.496[0.309,2.683]$ \\
\hline More than secondary completed & $5.970[4.627,7.313]$ & $4.024[2.910,5.138]$ & $4.024[2.910,5.138]$ & $0.6286[0.181,1.076]$ \\
\hline Urban & $7.109[6.050,8.169]$ & $4.515[3.659,5.371]$ & $4.489[3.635,5.342]$ & $1.563[1.051,2.075]$ \\
\hline Rural & $8.097[6.942,9.252]$ & $6.743[5.681,7.805]$ & $6.713[5.653,7.772]$ & $4.302[3.443,5.162]$ \\
\hline Media-Yes & $5.821[4.611,7.029]$ & $3.889[2.891,4.888]$ & $3.889[2.891,4.889]$ & $1.171[0.616,1.727]$ \\
\hline Media-No & $8.820[7.799,9.841]$ & $7.111[6.185,8.037]$ & $7.066[6.144,7.989]$ & $4.546[0.615,1.727]$ \\
\hline Knowledge-Yes & $7.359[6.551,8.168]$ & $5.674[4.958,6.391]$ & $5.667[4.951,6.382]$ & $12.045[8.834,15.256]$ \\
\hline Knowledge-No & $12.734[9.446,16.023]$ & $9.639[6.728,12.551]$ & $9.343[6.472,12.214]$ & 2.659 [2.161, 3.157] \\
\hline Smoking allowed at home-Yes & $25.963[21.676,30.251]$ & $23.205[19.077,27.332]$ & $22.897[18.789,27.006]$ & $9.178[6.354,12.001]$ \\
\hline Smoking allowed at home-No & $5.863[5.135,6.591]$ & $4.176[3.556,4.796]$ & $4.176[3.556,4.795]$ & $2.739[2.234,3.2458]$ \\
\hline
\end{tabular}


Table A3: Decomposition of the concentration index, daily tobacco smokers

\begin{tabular}{lrrrr}
\hline Variables & Elasticity & $\begin{array}{l}\text { Concentration } \\
\text { index }\end{array}$ & $\begin{array}{l}\text { Contribution to } \\
\mathbf{C}_{\mathbf{K}}=-\mathbf{0 . 1 8 9}\end{array}$ & $\begin{array}{l}\text { Percentage } \\
\text { contribution }\end{array}$ \\
\hline Gender & 0.366 & 0.045 & 0.016 & -8.703 \\
Age1 (years), 15-24 & -0.163 & 0.006 & -0.001 & 0.490 \\
Age2 (years), 25-44 & 0.014 & 0.081 & 0.001 & -0.593 \\
Age3 (years), 45-64 & 0.029 & -0.065 & -0.002 & 1.009 \\
Wealth-Q1 & 0.077 & -0.920 & -0.070 & 37.238 \\
Wealth-Q2 & 0.021 & -0.427 & -0.009 & 4.853 \\
Wealth-Q3 & 0.054 & 0.033 & 0.002 & -0.936 \\
Wealth-Q4 & 0.029 & 0.541 & 0.016 & -8.205 \\
No formal education & -0.014 & -0.575 & 0.008 & -4.169 \\
Less than primary school completed & 0.025 & -0.304 & -0.007 & 3.963 \\
Primary school completed & 0.021 & -0.002 & 0.0001 & 0.027 \\
Less than secondary completed & -0.008 & 0.085 & -0.001 & 0.347 \\
Urban & -0.023 & 0.532 & -0.012 & 6.567 \\
Media & -0.047 & 0.395 & -0.019 & 9.908 \\
Knowledge & -0.093 & 0.296 & -0.027 & 14.542 \\
Smoking allowed at home & 0.047 & -0.180 & -0.008 & 4.465 \\
Residual & & & -0.083 & 43.663 \\
Total & & & $\mathbf{0 . 1 8 9}$ & $\mathbf{1 0 0 . 0 0 0}$ \\
\hline
\end{tabular}


Table A4: Decomposition of the concentration index, daily cigarette smokers

\begin{tabular}{lrlrr}
\hline Variables & Elasticity & $\begin{array}{l}\text { Concentration } \\
\text { index }\end{array}$ & $\begin{array}{r}\text { Contribution } \\
\text { to } \mathbf{C}_{\mathbf{K}}=\mathbf{- 0 . 1 8 7}\end{array}$ & $\begin{array}{l}\text { Percentage } \\
\text { contribution }\end{array}$ \\
\hline Gender & 0.372 & 0.045 & 0.017 & -8.945 \\
Age1 (years), 15-24 & -0.153 & 0.006 & -0.001 & 0.466 \\
Age2 (years), 25-44 & 0.021 & 0.081 & 0.002 & -0.914 \\
Age3 (years), 45-64 & 0.033 & -0.065 & -0.002 & 1.131 \\
Wealth-Q1 & 0.078 & -0.920 & -0.072 & 38.274 \\
Wealth-Q2 & 0.022 & -0.427 & -0.009 & 4.988 \\
Wealth-Q3 & 0.052 & 0.033 & 0.002 & -0.908 \\
Wealth-Q4 & 0.029 & 0.541 & 0.016 & -8.434 \\
No formal education & -0.014 & -0.575 & 0.008 & -4.285 \\
Less than primary school completed & 0.025 & -0.304 & -0.008 & 4.073 \\
Primary school completed & 0.022 & -0.002 & 0.0001 & 0.028 \\
Less than secondary completed & -0.008 & 0.085 & -0.001 & 0.356 \\
Urban & -0.024 & 0.532 & -0.013 & 6.750 \\
Media & -0.048 & 0.395 & -0.019 & 10.184 \\
Knowledge & -0.079 & 0.296 & -0.023 & 12.455 \\
Smoking at home & 0.046 & -0.180 & -0.008 & 4.437 \\
Residual & & & -0.084 & 44.781 \\
Total & & & $-\mathbf{0 . 1 8 7}$ & $\mathbf{1 0 0 . 0 0 0}$ \\
\hline
\end{tabular}


Table A5: Decomposition of the concentration index, daily smokeless tobacco users

\begin{tabular}{lrrrr}
\hline Variables & Elasticity & $\begin{array}{c}\text { Concentration } \\
\text { index }\end{array}$ & $\begin{array}{c}\text { Contribution } \\
\text { to } \mathbf{C}_{\mathbf{K}}=\mathbf{- 0 . 4 4 7}\end{array}$ & $\begin{array}{c}\text { Percentage } \\
\text { contribution }\end{array}$ \\
\hline Gender & 0.131 & 0.045 & 0.006 & -1.320 \\
Age1 (years), 15-24 & -0.324 & 0.006 & -0.002 & 0.413 \\
Age2 (years), 25-44 & -0.237 & 0.081 & -0.019 & 4.272 \\
Age3 (years), 45-64 & -0.038 & -0.065 & 0.002 & -0.556 \\
Wealth-Q1 & 0.008 & -0.920 & -0.007 & 1.661 \\
Wealth-Q2 & 0.024 & -0.427 & -0.010 & 2.300 \\
Wealth-Q3 & -0.032 & 0.033 & -0.001 & 0.237 \\
Wealth-Q4 & -0.017 & 0.541 & -0.009 & 2.074 \\
No formal education & 0.127 & -0.575 & -0.073 & 16.338 \\
Less than primary school completed & 0.081 & -0.304 & -0.025 & 5.510 \\
Primary school completed & 0.038 & -0.002 & -0.0001 & 0.021 \\
Less than secondary completed & 0.031 & 0.085 & 0.003 & -0.592 \\
Urban & -0.052 & 0.532 & -0.028 & 6.226 \\
Media & -0.043 & 0.395 & -0.017 & 3.757 \\
Knowledge & -0.305 & 0.296 & -0.090 & 20.219 \\
Smoking at home & 0.045 & -0.180 & -0.008 & 1.806 \\
Residual & & & -0.176 & 39.440 \\
Total & & & $\mathbf{- 0 . 4 4 7}$ & $\mathbf{1 0 0 . 0 0 0}$ \\
\hline
\end{tabular}

